\title{
Introduction: The Fogarty International Research Ethics Education and Curriculum Development Program in Historical Context
}

\author{
JosePH Millum \\ National Institutes of Health \\ Christine Grady \\ National Institutes of Health \\ Gerald Keusch \\ Boston University \\ BARBARA SINA \\ National Institutes of Health
}

\begin{abstract}
IN RESPONSE TO THE INCREASING NEED for research ethics expertise in low- and middleincome countries (LMICs), the NIH's Fogarty International Research Ethics Education and Curriculum Development Program has provided grants for the development of training programs in international research ethics for LMIC professionals since 2000. This collection of papers draws upon the combined expertise of Fogarty grantees, trainees, and other experts to assess the state of research ethics in LMICs, and the lessons learned over 12 years of international research ethics education; to assess future needs; and to chart a way forward to meet those needs. In this introductory paper we briefly sketch the evolution of research ethics as applied to LMIC research, the underpinning and evolution of the Fogarty bioethics program, and summarize key conclusions from the other papers in the collection.
\end{abstract}

KEY WORDS: Fogarty International Center, research ethics, bioethics, training, education, curriculum, history

Received: June 25, 2013; revised: November 4, 2013

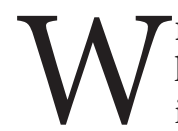

HEN HEALTH RESEARCH TAKES PLACE IN low- and middle-income countries (LMICs), in which many potential participants are poor, lack access to good quality health care outside of research studies, have little political power, and may be illiterate and unfamiliar with modern medicine, concerns about exploitation and other potential ethical violations are heightened. The fact that most of the health research conducted in LMICs is sponsored by multinational pharmaceutical companies and research funding institutions in high-income countries (HICs) may further fuel concerns. While this research can be extremely important and have beneficial impacts on the health of LMIC populations, before it proceeds it requires careful scrutiny by people with scientific and ethical expertise who understand the cultural and socio-economic context in which it will take place.

In response to the increasing need for research ethics expertise in LMICs, the NIH's Fogarty International Research Ethics Education and Curriculum Development Program has provided grants for the development of training programs in research ethics for LMIC professionals since 2000 (Fogarty International Center [FIC], 2012). Grantees, selected after rigorous independent peer review, receive support to develop socioculturally relevant, graduate-level international research ethics curricula for LMIC participants, including foundational ethical theory, international guidance, research case studies, and relevant practicum experiences. The training centers invite LMIC researchers, health professionals, and academics to apply for a mentored 1-2 year training experience and reentry activities at their home institutions, fully supported by the Fogarty grant. This training is expected to prepare participants to lead ethical review of research in their home setting, to contribute to an international discussion of research ethics issues in LMICs, to train others in research ethics, and to develop, implement, and disseminate research ethics guidance.

Twelve years after the inception of the program, the global health research landscape has evolved. Within research ethics, there remains a commitment to core principles, but attention has focused more on the nuances of how to apply fundamental research ethics principles to the increasingly complex realm of health research (Table 1). Despite the increase in the number of formally educated bioethicists in developing countries, the need for ethical expertise in the design, review, and

Journal of Empirical Research on Human Research Ethics, Vol. 8, No. 5, PP. 3-16. PRINT ISSN 1556-2646, ONLINE ISSN 1556-2654. (c) 2013 BY JOAN SIEBER. ALL RIGHTS RESERVED. PLEASE DIRECT ALL REQUESTS FOR PERMISSIONS TO PHOTOCOPY OR REPRODUCE ARTICLE CONTENT THROUGH THE UNIVERSITY OF CALIFORNIA PRESS'S RIGHTS AND PERMISSIONS WEBSITE, HTTP://WWW.UCPRESSJOURNALS.COM/REPRINTINFO.ASP. DOI: $10.1525 /$ jer.2013.8.5.3 
TABLE 1. Evolving International Research Ethics Landscape.

\begin{tabular}{lll} 
Early concerns & Transitions beginning late 1990s & Current \\
Exploitation, helicopter research & $\begin{array}{c}\text { Responsiveness and post-trial planning to minimize } \\
\text { exploitation } \\
\text { Capacity building }\end{array}$ & $\begin{array}{c}\text { Collaborative partnerships, benefit } \\
\text { sharing, responsiveness } \\
\text { Partnership, community engagement, } \\
\text { capacity building }\end{array}$ \\
$\begin{array}{c}\text { Inappropriateness of Western } \\
\text { norms such as informed consent }\end{array}$ & $\begin{array}{c}\text { Expanding commitment to individual informed consent, } \\
\text { Continued commitment to improving } \\
\text { informed consent everywhere } \\
\text { Standards of care in study design }\end{array}$ & $\begin{array}{c}\text { Standards of care, ancillary care, } \\
\text { post-trial care }\end{array}$ \\
\hline
\end{tabular}

conduct of health research in LMICs has only expanded as the amount of research in LMICs has increased. This collection of papers draws upon the combined expertise of many of the Fogarty grantees, trainees, and other affiliated experts to assess the state of research ethics in LMICs and the lessons learned over 12 years of international research ethics education, to identify future needs, and to chart a way forward to help meet those needs.

This collection includes five regional papers, covering Sub-Saharan Africa, Asia, Central and Eastern Europe, Latin America, and the Middle East. In addition, topical papers address mentoring, scholarly productivity, curriculum analysis, teaching about vulnerability, Asian perspectives on ethics, identifying policy gaps in research ethics, methods for evaluating ethics education programs, and distance learning. In this introductory paper we sketch the development of research ethics as applied to LMIC research, describe the underpinning and evolution of the Fogarty research ethics program, and summarize some key conclusions from the collection.

\section{INTERNATIONAL RESEARCH ETHICS BEFORE 2000}

Concerns about the ethics of conducting risky medical experiments on humans in an international context date back more than a century (Timeline). In 1898, in Prussia, Albert Neisser was fined for experimentally injecting patients with syphilitic serum without their consent (Vollmann \& Winau, 1996). Two years later, Walter Reed's well-known yellow fever experiments in Cuba included volunteers who signed consent forms agreeing to be exposed to transmission of the virus from mosquitoes, despite the fact that no treatment was available (Lederer, 2008). The President's Advisory Commission on Human Radiation Experiments found that "as early as 1944 it was conventional for physicians and other biomedical scientists to obtain consent from healthy subjects of research." However, "physicians engaged in clinical research [on sick patients] generally did not obtain consent from patient-subjects" (Advisory Committee on Human Radiation Experiments, 1996, Finding 10).
Much has been written about the medical experiments undertaken by Nazi physicians during World War II and their trial at the Nuremberg Military Tribunals, where they were charged with war crimes and crimes against humanity (Weindling, 2008). However, some unethical international medical research continued after the war. Between 1946 and 1948 U.S. government researchers conducted experiments in Guatemala that involved deliberately infecting subjects with venereal diseases, including syphilis, without their consent. A recent report investigating these unethical experiments suggests attitudes that may have been typical of medical researchers at the time:

...investigators were operating within a culture of medical research that often treated moral norms pragmatically, primarily as defenses against meddling "do-gooders" who would impinge upon their all-important work, rather than genuine moral imperatives based on respect for persons. (Presidential Commission for the Study of Bioethical Issues, 2011, p. 97)

Concerns about ongoing unethical research were subsequently raised by Henry Beecher in the U.S. and Maurice Pappworth in the U.K. (Beecher, 1966; Pappworth, 1962, 1967). International guidance for conducting research involving human subjects was made explicit in the World Medical Association's Declaration of Helsinki in 1964.

The few discussions of the ethics of international health research over the next few years were primarily among academic researchers in HICs, especially regarding "helicopter" medical research, which entailed investigators from HIC institutions flying into an LMIC, taking patient specimens and data, and flying out without providing any benefit to the host community. Other commentators worried about "ethical imperialism"-imposing the ethical values and practices of the West on communities for whom these values were foreign. Some questioned, for example, whether the requirement for individual informed 
consent was appropriate in cultures who believed in the priority of the community or family over the individual. Commenting on this dilemma in 1979, Carl E. Taylor wrote:

Where most decisions about treatment are communal, is it only a facade to insist on individual consent? Does it not simplify and make more realistic and honest a process whereby community leaders give consent since individuals would follow their advice in any case? (Taylor, 1979, pp. 982-983)

However, it was the question of the "standard of care" offered to research participants in HIV/AIDS trials in developing countries that drew global attention to the special ethical issues that can arise with research in poor communities. Due to the cost of drugs, deficiencies in health infrastructure, and lack of routine prenatal care, it was impossible to implement the HIC standard of care to prevent mother to child HIV transmission in the LMICs where HIV was spreading most rapidly (Connor et al., 1994). Following a WHO meeting to evaluate the research agenda, a group of placebo-controlled trials of shortcourse zidovudine and other more LMIC-appropriate modalities for reducing perinatal HIV transmission were implemented in several high-incidence African, Asian, and Caribbean countries (Lavery et al., 2007).

In September 1997, Peter Lurie and Sidney Wolfe published an opinion piece in the New England Journal of Medicine criticizing these trials: "In our view, most of these trials are unethical and will lead to hundreds of preventable HIV infections in infants" (Lurie \& Wolfe, 1997, p. 853).

The debate over the placebo-controlled perinatal HIV studies of "short-course AZT" polarized ethical discussion. On the one side were those who thought that conducting placebo-controlled trials when there existed proven effective treatments showed unethical "double standards" between rich and poor countries (Angell, 1997). Others thought that the local context was essential to determining whether a clinical trial was ethical (Varmus \& Satcher, 1997, pp. 1003-1004). Edward Mbidde, Chairman of the AIDS Research Committee of the Uganda Cancer Institute, wrote:

Ugandan studies are responsive to the health needs and the priorities of the nation. Research subjects have been selected in such a way that the burdens and benefits of the research will be equitably distributed, and the appropriate authorities, including the national ethics review committee, have satisfied themselves that the research meets their own ethical requirements. With these requirements met, if
Ugandans cannot carry out research on their people for the good of their nation, applying ethical standards in their local circumstances, then who will? (Mbidde, 1998, p. 836)

But among the 13 letters of correspondence from 25 authors the New England Journal of Medicine published in response to the Lurie and Wolff and Angell critiques, just four authors were identified as from LMIC institutions.

\section{The Fogarty International Center's Research Ethics Program}

DEVELOPMENT OF THE PROGRAM

In the wake of the debate over the perinatal HIV transmission trials, it was clear that insufficient attention was paid to voices from LMICs on the ethics of clinical research that directly affected their populations. In November 1999, under Director Gerald Keusch, FIC organized the first in a series of meetings of the Global Forum on Bioethics in Research (www.gfbronline. com/), which discussed LMIC clinical trials and the need for long-term training in research ethics. Karen Hofman, then at FIC, summed up its conclusions:

The participants agreed ... that a consortium of sponsors is urgently needed to develop a long-term training initiative in the bioethics of research, which would be offered in various countries. This new paradigm of support for international activities would have positive trans-cultural implications and help establish linkages between research funded by various international organizations and capacity development in bioethics. (Hofman, 2000, p. 175)

FIC has a long history of supporting collaborative research and research training programs between U.S. and LMIC institutions, which have been successful at building sustainable capacity in scientific research. Although some short-term research ethics training had been offered in various LMICs at the time of the Forum, there was a lack of in-depth internationally focused research ethics curricula and faculty with sufficient international research ethics expertise. Following the Global Forum, FIC settled on two primary goals for international research ethics training grant proposals, which were encompassed in a request for applications issued in 2000:

(1) Develop socioculturally relevant master's level international research ethics curricula covering foundational ethical theory, international 
research ethics guidance, LMIC research case studies, and ethics practicum experiences (e.g., research review, pedagogy, consultation, policy, and regulation).

(2) Provide in-depth training in research ethics to LMIC researchers, health professionals, and academics in positions to have an immediate impact at their institutions (e.g., train others in research ethics, lead ethics review, develop institutional, national, and international ethics guidance for research, and contribute to ethical debate on LMIC research issues).

INVOLVEMENT OF LMIC INSTITUTIONS AND FACULTY

In eight calls for proposals since 2000, 36\% of 165 total applications have been submitted from LMIC institutions, and $44 \%$ of all applications from LMIC institutions have been funded (in Argentina, Bangladesh, Brazil, Chile, China, India, Nigeria, Pakistan, Philippines, Russia, South Africa, and Uganda), compared to $39 \%$ from U.S. institutions. Among the 60 grants funded through 2011, 43\% were awarded to LMIC institutions, compared to $48 \%$ to U.S. institutions and $8 \%$ to non-U.S. HIC institutions (in Canada and Australia). In order to encourage applications from the research ethics community and LMIC institutions not familiar with the NIH grants process, FIC also provided grants writing workshops and offered small two-year planning grants to LMIC applicants to plan curricula, strengthen faculty, and meet with collaborators. $71 \%$ of the initial awards to LMIC grantees were for planning grants. Afterwards, $55 \%$ of planning grantees submitted successful full training applications. All subsequently competed successfully for renewal grants 4 or 5 years later. By comparison, only $33 \%$ of LMIC applications funded for full training programs on their initial proposal were able to secure renewal support.

Although collaboration is not required, HIC applicants have always been strongly encouraged to include LMIC faculty and advisory committee members. Some LMIC trainees with faculty members or co-directors in HICbased training institutions have applied successfully for a training grant for their home institutions. When $\mathrm{NIH}$ policy changed in 2006 to allow multiple principal investigators to be designated on a single application, many subsequent HIC applications included LMIC collaborators as principal investigators. Increasing numbers of $\mathrm{HIC}$ programs conduct the majority of their training activities at LMIC partner institutions.

\section{ADDRESSING TRAINEE NEEDS}

Since 2000, 20 training programs have graduated approximately 600 long-term trainees from 74 LMICs, the majority with health professional backgrounds (Matar et al., forthcoming). While strengthening of RECs has not been a direct goal of the program, it has an indirect impact on them by helping to develop human capacity in participating LMIC countries. Education on REC regulations, operations, and the skills needed for effective REC operation are widely included in program curricula (Matar et al., forthcoming).

English is increasingly the unofficial common language of science. However, the nuances of language are critical to the expression and understanding of ethical concepts. HIC institutions offering training to participants from non-English speaking countries now provide didactic training at collaborating LMIC institutions in local languages, including Spanish, French, Urdu, and Chinese.

People's understandings of ethics are also a product of culture. Pratt et al. in their literature review of perspectives from South and East Asia on clinical and research ethics examine the English language literature of relevance to bioethics in four Asian countries (Pratt et al., forthcoming). Their analysis illuminates the relationship between the foundational ethical and religious concepts of these countries and the dominant AngloAmerican views, presents data on how relationships between doctors and patients or research participants are evolving, and cautions against the mindless imposition of "international standards," which might then be adopted in name only. The analysis of program curricula suggested that while some program directors thought that there were concerns about the influence of Western bioethical concepts, others did not, and many had incorporated discussions of secular Western and indigenous or religious value systems into their curricula (Matar et al., forthcoming). Faculty in another training program found that new trainees from Russia and Romania lacked an understanding of the current, widely accepted concept of "vulnerability" and an appreciation for the need to protect vulnerable populations in research. Loue and Loff (2013a, this issue) consider the political and cultural conditions that might have fostered this problem and describe educational interventions developed to address it.

\section{DISTANCE LEARNING}

The evolution of electronic communication technologies during the lifespan of the program offered new tools for education. FIC funded the first distancelearning research ethics training grant from an $\mathrm{HIC}$ 
institution for an LMIC region in 2004. Subsequently, additional training sites have incorporated hybrid distance-learning approaches into their curricula as Internet access, appropriate technology, and adaptable electronic training resources have emerged. Silverman et al. (2013, this issue) conducted an evaluation of four current online courses using a combination of faceto-face and distance-learning approaches to identify areas for quality improvement. The results show that the courses meet most of the best practice criteria for the field of online courses. They also suggest that continued sharing of expertise and experiences could support all the courses to meet best practice criteria where deficiencies exist.

\section{SCHOLARSHIP}

FIC trainees have made important contributions to the international bioethics literature, particularly with regard to HIV/AIDS and TB research, vaccine research, biotechnology research, ethical review committees, community engagement, and informed consent. While the 20 most-cited trainee publications were primarily published in high-impact international journals (6 in PloS Medicine, 4 in Social Science and Medicine, 3 in Journal of Medical Ethics, and 2 in Nature Biotechnology), trainees also contributed to the development or expansion of national or regional journals (including Romanian Journal of Bioethics, Indian Journal of Medical Ethics, Acta Bioethica, Revista Romana de Bioetica, and African Journal of Medicine and Medical Sciences). 12.6\% of trainee papers $(\mathrm{n}=328)$ published between 2004 and 2008 were cited more than 10 times (Fix et al., 2013, this issue).

\section{CRITICISM OF THE PROGRAM}

Although it has been widely supported, the FIC bioethics training program has also faced criticisms that it attempts to impose U.S. conceptions of research ethics on other cultures and serves the goals of the U.S. government and pharmaceutical industry by preparing foreign research sites to host their clinical trials. Ruth Chadwick and Udo Schüklenk commented in an editorial in Bioethics subtitled "Bioethical Colonialism?":

International agencies provide significant amounts of funding designed to improve research ethics capacity in the developing world. The strings attached: budding research ethicists in the developing world have to undergo "training" in institutions of the rich north, thereby implying that there is insufficient intellectual and personnel capacity locally to train ethicists.... [O]ne has reason to be sensitive to claims by developing world based bioethicists that much of this "training" really constitutes a form of ideology transfer. ...The current assumption seems to be that the developing world needs our training and needs to be subjected to significant doses of our ethical views and ideologies, instead of funding allowing it to develop its own capacities based on its own thinking. (Chadwick \& Schüklenk, 2004, pp. iii-iv)

Douglas Wassenaar, an FIC training program grantee at the University of KwaZulu-Natal in South Africa, commented on this misconception in the context of Africa on the Hastings Center Report blog:

To the best of my knowledge, not one of these programs ... aims to replicate the U.S. IRB system. Instead, they aim to enhance the ability of African researchers, scientists, research ethics committee members and other stakeholders to debate precisely the ethical issues ... and to generate ethically considered solutions to local ethical dilemmas, using the best international resources applied to deep knowledge of local conditions. (Wassenaar, 2006)

SYSTEM AND PROGRAM ANALYSIS

In the U.S., despite the vast amount of time and money invested into IRB review, there is agreement on the burden that ethics review places on researchers and institutions, but no data on whether the system protects research participants (Grady, 2010). Strosberg, Gefanas, \& Famenka (forthcoming) describe an analytical framework designed to identify gaps in the public policies establishing research ethics review systems that impede them from doing their job of protecting human research subjects and show how it can be applied to several exCommunist countries. Evaluating individual research ethics education programs also poses interesting challenges with regard to the identification of appropriate outcomes and ways to measure them. Ali et al. (forthcoming) describe a framework and tool that the Johns Hopkins University Fogarty African Bioethics Training Program developed for evaluating trainee professional accomplishments as well as the individual, institutional, and program-specific factors associated with posttraining success in research ethics.

\section{Where Are We Now?}

\section{THE CHANGING HEALTH RESEARCH LANDSCAPE}

Over the last few years the amount of research conducted in LMICs has continued to increase. Although in absolute numbers the top nine trial hosts are all still high-income countries, 24 of the fastest-growing 25 
trial site locations are LMICs (Thiers et al., 2008). Countries such as India and China still have a low density of trial sites by population and enormous potential for growth. Glickman et al. (2009) examined characteristics of 300 clinical trials reported in JAMA, Lancet, and NEJM in 1995 and 2005. In 1995, 33 countries were represented as trial site locations, whereas ten years later, it was 70. The proportion of trial sites located in Africa, Eastern Europe, and the Middle East increased while the proportion in the United States, Western Europe, and Asia decreased.

Most of this research is still sponsored by institutions based in HICs. Some of the increase is due to substantial increases in the funding directed towards global health (Bollyky, Cockburn, \& Berndt, 2010). However, some of the increase is a result of pharmaceutical companies taking advantage of the low costs of research in LMICs and the large numbers of treatment-naïve patients. When Glickman and colleagues looked at recruitment for industry-sponsored phase 3 clinical trials in 2007 they found:

...among the ongoing phase 3 clinical trials that we examined that were sponsored by U.S.-based companies in developing countries, none were trials of diseases such as tuberculosis that disproportionately affect the populations of these countries. In contrast, we found a variety of trials in developing countries for conditions such as allergic rhinitis and overactive bladder. (Glickman et al., 2009, p. 819)

\section{CURRENT DEBATES IN INTERNATIONAL RESEARCH ETHICS}

Questions about exploitation, consent, and the inappropriate imposition of Western norms and regulatory requirements continue to be raised. But over the past decade or so, the scope of ethical concerns about health research in LMICs has expanded, the discussion has become more sophisticated, and contributions from LMIC authors on these topics have become more numerous.

Questions about what is owed to participants in research studies no longer focus solely on the standard of care that should be provided as part of the scientific design of a clinical trial. Discussion has expanded to include the health care that participants should receive that is not part of the scientific design of the study (ancillary care) and the care that they should receive after trials are completed (post-trial benefits) (Sofaer \& Strech, 2011; Participants, 2008). The question of who should pay for these benefits remains unresolved. Literature has also examined the proper role of clinical research within theories of justice drawn from political philosophy (Millum \& Emanuel, 2012). The general agreement that "helicopter" research is ethically problematic has evolved to a greater focus on how research projects should be chosen and designed, including the importance of equitable partnerships with local scientists, and greater involvement of communities in all stages of the research process. Issues related to conflicts of interests have become more prominent. Recognition that communities, and even countries, could be exploited by research has led to discussion of the extent to which they should benefit from research, for example, by requiring that health research be responsive to the community's health needs or that the benefits of research be shared fairly with countries that provide the samples and data on which it is based. The increase in the amount of multinational research noted above, and the recent proliferation of biobanks, make these issues particularly pressing.

Research participants in developed and developing countries show variable understanding of key elements of informed consent, including the purpose of the research and its risks (Mandava et al., 2012). While there is wide agreement that all competent adults should give informed consent to research participation, the current focus is on how to improve the quality of informed consent. A variety of interventions, including shortened consent forms, talking books, culturally sensitive education, and tests of understanding are being evaluated in LMIC settings (Dawson \& Kass, 2005; Dhai, Etheredge, \& Cleaton-Jones, 2010; Fitzgerald et al., 2005).

LMIC voices are increasingly contributing to discussion of research ethics issues. When Borry, Schotsmans, and Dierickx (2006) investigated the geographical differences in research productivity in bioethics by looking at the affiliation of first authors of articles in nine leading "international" bioethics journals between 1990 and 2003, only three of the 21 most productive countries were LMICs: China, Turkey and South Africa. In the 4029 publications examined, Chinese first authors contributed 24, compared to 2390 from the U.S. In 2001, the journal Developing World Bioethics was launched, as the first international journal with an exclusive focus on issues in bioethics in LMICs. Along with PloS Medicine and Lancet, Developing World Bioethics was the international journal that published the largest number of FIC trainee publications between 2004 and 2008 (Fix et al., 2103, this issue). Although Fogarty research ethics trainees have published widely, these publications are clearly not sufficient to fill the gap identified 
by Borry and colleagues. Fogarty trainees published only 13 papers in the nine journals Borry and colleagues studied.

THE FOGARTY RESEARCH ETHICS PROGRAM IN 2012

In the last decade, the amount of research supported by NIH in LMICs increased substantially (Roger Glass, personal communication, 2013). In parallel, the annual program budget grew from approximately $\$ 1.5$ million to over $\$ 4$ million, which permitted increased training grant budgets and annual grant competitions. Figure 1 shows the regional distribution of funded Fogarty research ethics training grants over time. Sub-Saharan Africa-thought to have the least research ethics capacity when the program was initiated-represents the focus of the majority of applications and has averaged approximately $40 \%$ of total program funding over its lifespan. Training of participants from Latin America, Asia, and to a lesser extent, Eastern Europe has been supported continuously, but it was not until 2004 that training for the Middle East was proposed and funded. Figure 2 displays the accumulated geographic distribution of long-term trainees reported by the training sites. After more than a decade, the program has supported approximately 600 long-term research ethics trainees in 74 countries, thereby establishing a foundation of leadership and expertise worldwide.
Looking Ahead

THE GLOBAL PICTURE

Global health research will not thrive without a knowledgeable global discussion of the ethics of the research to shape its course. Given the expected further increases in the health research hosted by LMICs, more capacity will have to be built in order to ensure that human subjects protections are maintained even at present levels. Moreover, a number of commentators have noted the challenges that still face LMIC researchers and RECs. Bollyky et al. argue that one of the bottlenecks still impeding bringing new products for neglected diseases to patients is the inadequacy of the "research and regulatory capacity in many neglected disease-endemic settings" (2010, p. 726). They also note that neglected disease trials in disease-endemic countries pose particularly difficult ethical challenges.

Additional sources of support for research ethics activities for which LMIC trainees can apply have become available during the lifespan of the program. These include the Ethics and Society Program of the Wellcome Trust, the Ethics and Regulatory Projects of the European and Developing Countries Clinical Trials Partnership, and the Human Heredity and Health in Africa Ethical, Legal, and Societal Issues Research Program (H3Africa ELSI). In addition, new tools are now available; for example, the Council for Health Research and

\section{Program Distribution by Year}

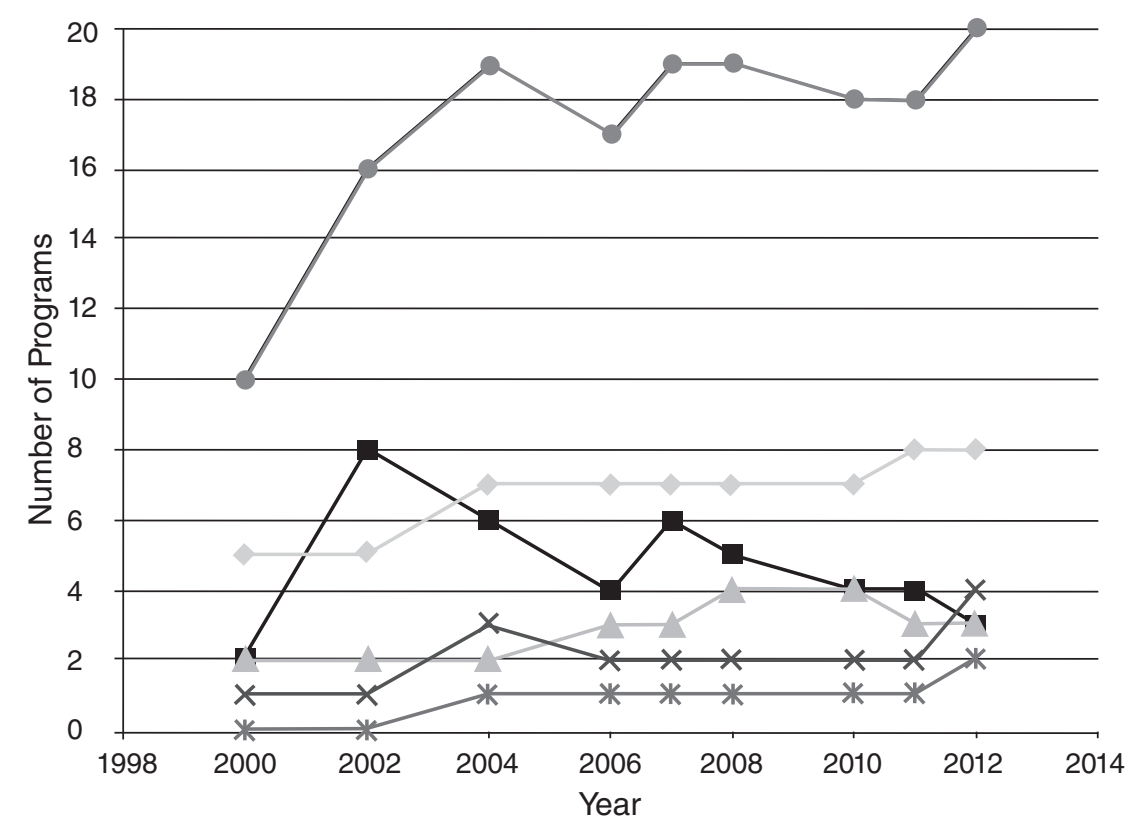

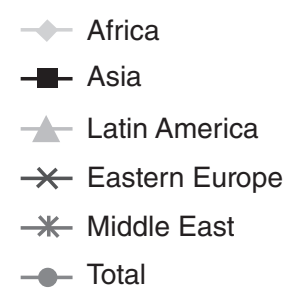

FIG.1. 


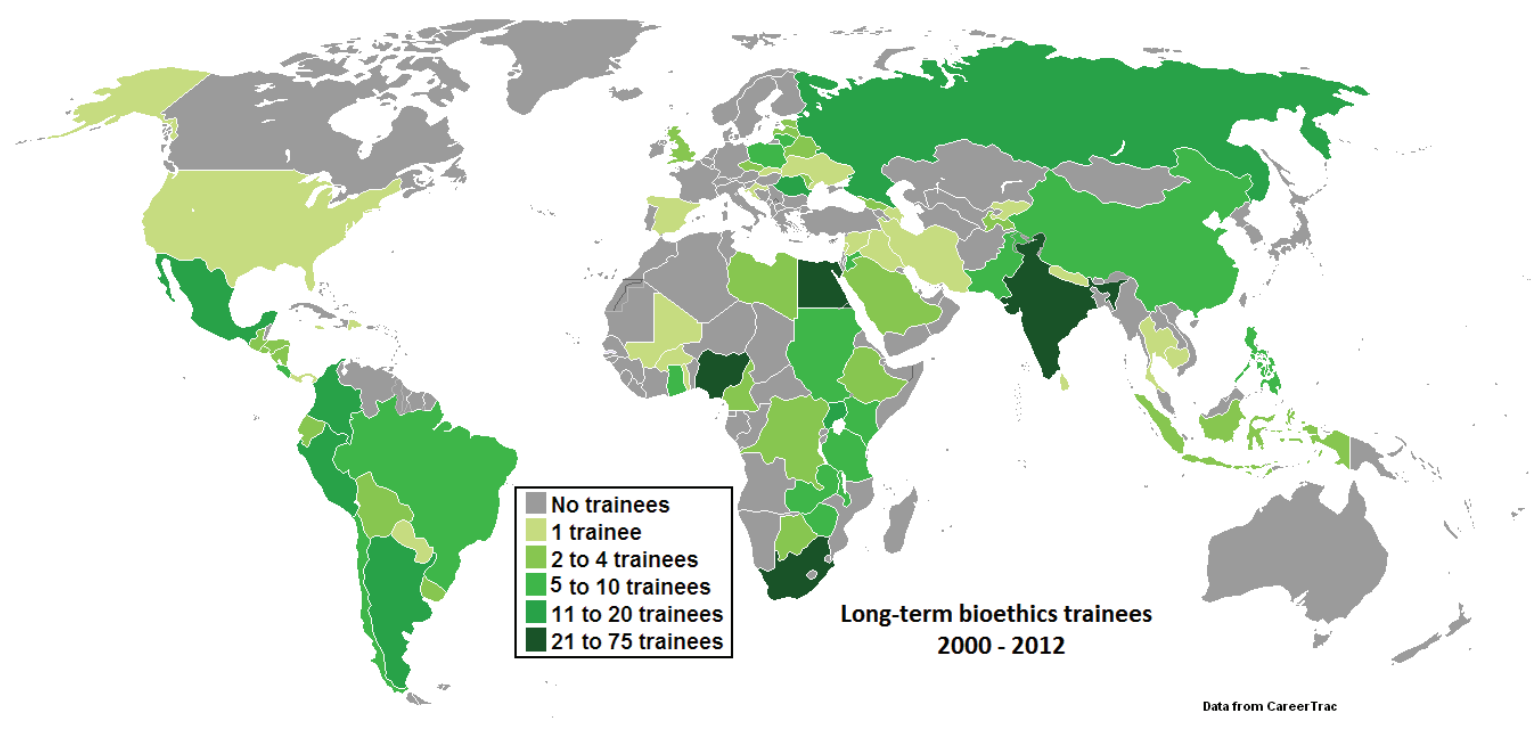

FIG. 2.

Development (COHRED) has developed a customizable web-based system to manage the process of ethical reviews (http://rhinno.net). Other sources of independent funding for LMIC research ethics doctoral and postdoctoral training - as well as research, health, and regulatory infrastructure-are needed in order to construct a viable lifelong career pipeline in the field and sustain research ethics capacity. Until sufficient support for effective and objective RECs at LMIC research institutions is provided by external or national sources (for example, indirect costs for research grants involving human subjects), the full benefit of ethics training for the protection of human subjects in research cannot be fully realized.

Career paths in bioethics for trainees and the sustainability of LMIC training sites remain ongoing concerns. Even in HICs, individual career paths in bioethics are often developed from a patchwork of short-term bioethics positions and funding opportunities. To support the career development of research ethics trainees, many of the funded programs provide courses in scientific proposal development and manuscript writing, and practicum experiences in IRB/REC review and management. Some also support reentry activities in teaching, research, or IRB-related projects at trainees' home institutions, and training directors and faculty provide long-term mentorship.

Mentorship is especially critical for trainees transitioning to careers where they are expected to apply new expertise as a pioneer in the field in their institutional setting. Loue and Loff (2013b, this issue) found that the most successful mentorship included orienting mentees to new responsibilities, a formalized, structured mentoring process, frequent contact with mentors, and psychosocial as well as academic support. Mentorship is not always included as part of traditional pedagogy, and therefore faculty may need training in mentorship processes and practices in order to enhance trainee success.

REGIONAL COMMONALITIES AND DIFFERENCES

In order to capture commonalities and regional differences in research ethics needs around the world, we surveyed the authors of the regional papers in this collection. We summarized the recommendations from each of the regional papers and sent a list of all recommendations to the lead author, asking him/her to rank the recommendations for his/her region according to whether it was a high priority, lower priority, not a priority, or unknown. Responses were received from the lead author or a designee for all five papers. The regional paper authors were unanimous in identifying the education of more trainees, the sustainability of their programs, and the career development of former trainees as a high priority (Table 2). Consistent with these priorities, it was widely agreed that trainees needed training in manuscript and grant writing, and post-training continuing education. Respondents also agreed on the need to engender enhanced critical thinking skills in trainees. Perceptions of the need for training in additional skills, such as leadership and advocacy, and specific curricula content were more varied. Outside of the Middle East, flexibility in the level of training (from awareness-building workshops up to support of doctoral-level research) was regarded 


\section{Timeline: International research ethics}

Walter Reed obtains written informed consent for healthy volunteers in his yellow fever experiments in Cuba

"Regulation on New Therapy and Experimentation" (Germany)

1900

1931

1932

1936

1944

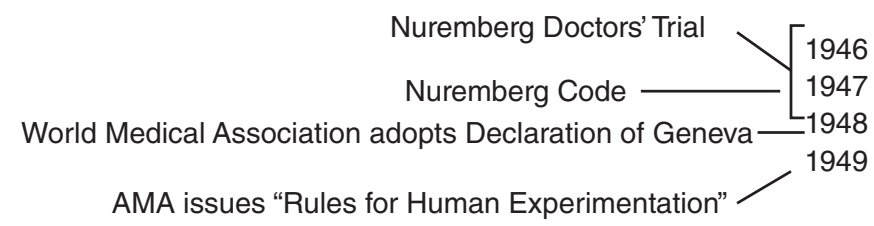

US FDA requires three phases of human clinical trials before approving a drug for public use

1962 1964

$\mathrm{NIH}$ creates the Office for Protection of Research Subjects and establishes IRBs

\section{Declaration of Helsink}

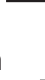

US National Research Act - Commission for the Protection of Human Subjects of Biomedical and Behavioral Research, which wrote the Belmont Report

CIOMS/WHO International Ethical Guidelines for Biomedical Research Involving Human Subjects UNESCO creates International Bioethics Committee 1993 1994

$$
1996
$$
1997

First Global Forum on Bioethics in Research 1999 FIC International Research Ethics training grants initiated — 2000 2001

\section{Creation of EDCTP 2003}

UNESCO - Universal Declaration on Bioethics and Human Rights

Initiation of Wellcome Trust's Ethics \& Society Program _ 2007

H3Africa Initiates ELSI grants

2013 Japan's Wartime Human Biowarfare Experimentation Program begins Manhattan Project
USPHS studies of sexually transmitted diseases in Guatemala
USPHS Tuskegee Syphilis Study begins

Maurice Pappworth publishes Human Guinea Pigs: A Warning in the U.K

NEJM publishes Henry Beecher's "Ethics and Clinical Research"

New York Times published front page story on USPHS Tuskegee Syphilis Study
Publication of results of AIDS Clinical Trial 076 Pfizer trial of a new antibiotic on children in Kona, - Nigeria during a meningitis outbreak. The company is later sued by Nigerian minors and their guardians

Lurie \& Wolfe, Angell NEJM editorials - NBAC Report on Clinical Trials in Developing Countries

FIG. 3. 
TABLE 2. Key Recommendations from Regional Papers. Regions: Asia (A), Central and Eastern Europe (E), Latin America (L), Middle East (M), Sub-Saharan Africa (S).

\begin{tabular}{|c|c|c|c|c|}
\hline Recommendation & High Priority & Lower Priority & Not a Priority & Don't Know \\
\hline \multicolumn{5}{|l|}{ Continuation } \\
\hline $\begin{array}{l}\text { Resources to educate more trainees still needed } \\
\text { Curriculum Enhancement }\end{array}$ & \multicolumn{4}{|c|}{ Curriculum Enhancement } \\
\hline Critical thinking & $A, L, M, S$ & $\mathrm{E}$ & & \\
\hline Research methodology & $L, M$ & $\mathrm{E}, \mathrm{S}$ & & \\
\hline Vulnerability and human rights & $\mathrm{E}$ & $\mathrm{S}$ & L & M \\
\hline Content that fits context and is culturally relevant & $A, E, S$ & M & L & \\
\hline $\begin{array}{l}\text { Flexibility in level (from awareness building work- } \\
\text { shops \& dissemination to lay public to PhDs \& } \\
\text { postdocs) }\end{array}$ & $A, E, L, S$ & & M & \\
\hline \multicolumn{5}{|l|}{ Post-Program Impact Skills and Support } \\
\hline Writing, publishing, grant-writing & $A, E, M, S$ & L & & \\
\hline Include former trainees in education & $A, E, M, S$ & L & & \\
\hline Leadership & $E, M, S$ & & L & \\
\hline Policy development & $E, M, S$ & L & & \\
\hline Advocacy & $E, M, S$ & & L & \\
\hline \multicolumn{5}{|l|}{ Improved Program Processes } \\
\hline $\begin{array}{l}\text { Goals and measures of success for bioethics } \\
\text { education }\end{array}$ & L, S & $\mathrm{E}$ & & M \\
\hline $\begin{array}{l}\text { Trainee selection: institutional support, senior } \\
\text { trainees, include REC administrators }\end{array}$ & $L, M, S$ & $\mathrm{E}$ & & \\
\hline Focus on institutional capacity building & $A, E, M, S$ & & L & \\
\hline Career development of former trainees & $A, E, L, M, S$ & & & \\
\hline Collect data on regional and country needs & $A, E, L, M, S$ & & & \\
\hline Sustainability of programs & $A, E, L, M, S$ & & & \\
\hline \multicolumn{5}{|l|}{ Enhanced Interaction among Programs } \\
\hline Trainee and mentoring networks & $A, E, L, M, S$ & & & \\
\hline REC networks & $L, M$ & ES & & \\
\hline $\begin{array}{l}\text { Share syllabi, education resources, faculty } \\
\text { exchange }\end{array}$ & $A, E, L, S$ & & M & \\
\hline $\begin{array}{l}\text { Coordinate with other training initiatives and } \\
\text { bioethics groups }\end{array}$ & $A, E, L, S$ & & M & \\
\hline
\end{tabular}

as a high priority. Likewise, outside of the Middle East, greater coordination and cooperation with other training initiatives and programs was seen as a high priority. This may reflect the fact that the Middle East Research Ethics Training Initiative (MERETI) program is the only program in the Middle East and strong networks already exist among its trainees. All regarded trainee and mentoring networks as high priorities.

The regional papers, our brief survey, and other publicly available data suggest that most countries still lack the critical mass of trainees required to tackle the research ethics training, consultation, regulatory, and ethical review needs of their research institutions and governments. For example, FIC programs have graduated approximately 100 long-term Latin American trainees. However, the PanAmerican Health Organization lists over 1000 Latin American RECs on Health Research Web (www. healthresearchweb.org/en/home). At the time of writing, 4772 clinical studies registered with ClinicalTrials.gov were located in South America, with another 1835 in Central America and 1812 in Mexico.

South Africa, India, Nigeria, and Egypt each have approximately 50 trainees. While these are populous countries with a multitude of research institutions, training programs in these locations foresee a future point where the primary challenge is ensuring sustainability and possibly more focused training, such as for REC administrators or PhDs who will constitute the next generation of local bioethics scholars.

\section{Best Practices}

The designers of future training programs in research ethics should pay particular attention to the following conclusions from the collection: 
(1) Programs should be flexible so that they can respond appropriately to the large differences in the existing capacities and needs of different regions and countries. Some countries have substantial in-country expertise and others require more external support. Some countries still need awareness-building workshops. Others now need diversification of training for specific roles, such as REC administration, scholarship on research ethics, and so on.

(2) Some LMIC countries are at a transition point, where sustainability requires developing advanced career paths in research ethics. Trainees with master's degrees need $\mathrm{PhDs}$, and postdoctoral research experience, since $\mathrm{PhDs}$ are internationally recognized as being able to offer leadership in their field.

(3) It is vital to consider how training will fit into and improve the overall system that governs human subjects research in the countries in which trainees work.

(4) Programs benefit enormously through collaboration, which includes collaboration between LMIC and HIC faculty and institutions within a grant, and collaboration between grantees linked in a network.

(5) Programs flourish through a process of ongoing feedback and revision, including through selfassessment via an independent advisory group, reporting of challenges in annual reports to which the program officer and others can respond, open grant re-competition based on progress reports, and revisions to improve the program every $4-5$ years. None of the Fogarty research ethics programs has remained the same since initiation.

(6) Finally, no single optimal educational model or program design for LMIC research ethics education has emerged, suggesting that different models are likely to fit different situations and that there are good reasons to keep experimenting.

In addition, individual research ethics educators should focus on the following:

(1) The critical role of mentoring and how this should be supported in a particular context.

(2) Understanding the different cultures and practices that may affect trainee understanding, learning styles, and how researchers and participants conduct themselves. They are likely to be variable, even within countries, and changing over time.
(3) The environments in which trainees will work make a huge difference to what they need to succeed (contrast the differing experiences of trainees returning to former Soviet countries).

\section{Research Agenda}

Many of the papers in this collection attempt systematic evaluations of the success of different aspects of research ethics education, for example, applying a framework for evaluating ethics review systems, conducting a quantitative analysis of publications, or synthesizing mentoring experiences. Frequently, these are the first attempts to conduct these types of evaluations in the context of long-term international research ethics training. Moving forward, further development and application of these methods would help the task of finding ways to measure, and thereby improve, the effectiveness of research ethics education. The multiple programs around the world also present an opportunity to compare how sustainable programs and career paths are built in a new field. Finally, the effects of systems of ethical review are notoriously difficult to assess. Work remains to be done to determine the long-term impact - on health research and the rights and welfare of research participants-of the global spread of bioethics expertise over the last decade.

\section{This Collection}

This collection of papers grew out of discussions regarding the best approaches to evaluating the impact of this nontraditional training program at annual grantee meetings. Participants thought that a collaborative grantee and program staff self-assessment of the program would capture the benefits of the deep knowledge in international research ethics education gained through more than a decade of experience. Publishing the results of the assessment in a peer-reviewed journal would satisfy the need for independent, objective evaluation. It was also thought that such a process would answer the most relevant questions regarding achievements and gaps, identify best practices, and give direction to those who could readily incorporate these results into their training programs. The grantees identified cross-cutting paper topics and volunteered to collaborate on writing one or more articles. Grantees who wished to conduct collaborative research for a paper could apply for competitively selected supplemental funds. Collaborative writing groups with a lead author presented plans and drafted initial manuscripts at a four-day writing retreat, which were subsequently finalized and shared 
electronically with all participants for comment. Revised manuscripts were edited by the FIC bioethicist and program official in collaboration with the lead authors before submission for publication.

The collection of papers represents the emergence of a community of practice for international research ethics education. It has two main purposes. First, it attempts to provide, in historical and social context, a picture of the current state of international research ethics education and research ethics capacity. Though this picture is formed through the experiences of the Fogarty research ethics grantees, it is not just a description of what they have achieved, but also their understanding of the research ethics landscape more broadly. Second, the collection presents some of the key lessons about research ethics education that the Fogarty grantees have learned. These include lessons about how to develop training curricula, how to teach research ethics, how to measure and present the impact of research ethics education, and teaching in different socioeconomic and cultural contexts.

Disclaimer: The views expressed are the authors' own. They do not represent the position or policy of the National Institutes of Health, U.S. Public Health Service, or the Department of Health and Human Services.

\section{Acknowledgments}

The authors thank Mili Ferreira for the timeline, Celia Wolfman for data gathering and map design, Joan Sieber for wise editorial guidance, an anonymous reviewer for comments, and the Fogarty grantees who provided feedback.

\section{Author Note}

Correspondence may be addressed to Joseph Millum, Clinical Center Department of Bioethics/Fogarty International Center, National Institutes of Health, Building 10, 1C118, 10 Center Drive, Bethesda, MD 20892. E-MAIL: joseph.millum@nih.gov.

\section{Authors' Biographical sketches}

Joseph Millum serves as a liaison between the Clinical Center Department of Bioethics and the Division of International Science Policy, Planning, and Evaluation at the Fogarty International Center, where he provides ethics consultation and educational support. His current research focuses on the rights and responsibilities of parents, global justice and bioethics, priority setting for global health, and international research ethics.

Christine Grady is Chief of the Department of Bioethics at the National Institutes of Health Clinical Center. Her research focuses on the ethics of clinical research, especially subject recruitment, incentives, vulnerability, informed consent, and international research ethics. She is currently a member of the Presidential Commission for the Study of Bioethical Issues, a senior research fellow at the Kennedy Institute of Ethics, and an elected fellow at the Hastings Center and the American Academy of Nursing.

Gerald Keusch is Associate Director of the National Emerging Infectious Diseases Laboratory at Boston University, and the previous Director of the Fogarty International Center at the National Institutes of Health. He is a member of the Institute of Medicine at the National Academies of Science and Chair of the Board of the Council on Health Research for Development (COHRED), a Geneva-based international NGO working to build capacity toward an effective national research and innovation system for health, equity, and development in low- and middle-income countries.

Barbara Sina is the Program Officer for the International Research Ethics Education and Curriculum Development Program in the Division of International Training and Research, Fogarty International Center, National Institutes of Health.

\section{References}

Advisory Committee On Human Radiation Experiments (Ruth Faden, Chair). (1996). The human radiation experiments: Final report of the President's Advisory Committee on Human Radiation Experiments, New York: Oxford University Press.

Ali, J., Hyder, A., \& Kass, N. (forthcoming) An Empirical Approach for Evaluating Research Ethics Capacity Development Programs (working title). Journal of Empirical Research on Human Research Ethics.
Angell, M. (1997). The ethics of clinical research in the third world. New England Journal of Medicine, 337, 847-849.

Beecher, H. K. (1966). Ethics and clinical research. New England Journal of Medicine, 274, 367-372.

Bollyky, T. J., Cockburn, I. M., \& Berndt, E. (2010). Bridging the gap: Improving clinical development and the regulatory pathways for health products for neglected diseases. Clinical Trials, 7, 719-734. 
Borry, P., Schotsmans, P., \& Dierickx, K. (2006). How international is bioethics? A quantitative retrospective study. BMC Medical Ethics, 7(1). Retrieved from www.biomedcentral. com/1472-6939/7/1.

Chadwick, R., \& Schüklenk, U. (2004). From the editors: Bioethical colonialism? Bioethics, 18(5), iii-iv.

Coleman, C. H., \& Bouësseau, M. C. (2008). How do we know that research ethics committees are really working? The neglected role of outcomes assessment in research ethics review. BMC Medical Ethics, 9(6). Retrieved from www. biomedcentral.com/1472-6939/9/6.

Connor, E. M., Sperling, R. S., Gelber, R., Kiselev, P., Scott, G., O’Sullivan, M. J., ET AL. (1994). Reduction of maternalinfant transmission of human immunodeficiency virus type 1 with zidovudine treatment. New England Journal of Medicine, 331, 1173-1180.

Dawson, N., \& Kass, N. E. (2005). Views of U.S. researchers about informed consent in international collaborative research. Social Science and Medicine, 61(6), 1211-1222.

Dhai, A., Etheredge, H., \& Cleaton-Jones, P. (2010) A pilot study evaluating an intervention designed to raise awareness of clinical trials among potential participants in the developing world. Journal of Medical Ethics, 36(4), 238-242.

Fitzgerald, D. W., Marotte, C., Verdier, R. I., Johnson, W. D., \& PAPE, J. W. (2002) Comprehension during informed consent in a less-developed country. Lancet, 360(9342), 1301-1302.

Fix, J., Odell, J., Sina, B., Meslin, E., Goodman, K., \& Upshur, R. (2013, this issue). Bibliometric analysis of the trainee scholarship of the Fogarty International Center's International Research Ethics Education and Curriculum Development Award. Journal of Empirical Research on Human Research Ethics, 8(5).

Fogarty International Center. (2012). International Research Ethics Education and Curriculum Development Award (Bioethics). Retrieved from www.fic.nih.gov/programs/pages/ bioethics.aspx.

Glickman, S. W., McHutchison, J. G., Peterson, E. D., Cairns, C. B., Harrington, R. A., Califf, R. M., \& Schulman, K. A. (2009). Ethical and scientific implications of the globalization of clinical research. New England Journal of Medicine, 360(8), 816-823.

Grady, C. (2010). Do IRBs protect human research participants? Journal of the American Medical Association, 304(10), 1122-1123.

Hofman, K. (2000). The global forum for bioethics in research: Report of a meeting, November 1999. Journal of Law and Medical Ethics, 28(2), 174-175.

Ivy, A. C. (1949). Nazi war crimes of a medical nature: Some conclusions. Journal of the American Medical Association, 139(3), 131-135.

Lavery, J. V., Grady, C., Wahl, E. R., \& Emanuel, E. J. (2007). Introduction. In J. V. Lavery et al. (Eds.), Ethical issues in international biomedical research: A casebook (pp. 3-18). New York: Oxford University Press.

LEDERER, S. E. (2008). Walter Reed and the yellow fever experiments. In E. J. Emanuel et al. (Eds.), The Oxford textbook of clinical research ethics (pp. 9-17). New York: Oxford University Press.

Loue, S., \& Loff, B. (2013a, this issue). Is there a universal understanding of vulnerability? Experiences with Russian and Romanian trainees in research ethics. Journal of Empirical Research on Human Research Ethics, 8(5).

Loue, S., \& Loff, B. (2013b, this issue). Mentoring international research ethics trainees: Identifying best practices. Journal of Empirical Research on Human Research Ethics, $8(5)$.

Lurie, P., AND Wolfe, S. M. (1997). Unethical trials of interventions to reduce perinatal transmission of the human immunodeficiency virus in developing countries. New England Journal of Medicine, 337, 853-856.

Mandava, A., Pace, C., Campbell, B., Emanuel, E., \& Grady, C. (2012). The quality of informed consent: Mapping the landscape-A review of empirical data from developing and developed countries. Journal of Medical Ethics, 38(6), 356-365.

Matar, A., Garner, S., Millum, J., Sana, B., \& Silverman, H. (forthcoming). Curricular aspects of the Fogarty Bioethics International training programs. Journal of Empirical Research on Human Research Ethics.

Mbidde, E. K. (1997). Letter to the editor. New England Journal of Medicine, 338, 836.

Millum, J., \& Emanuel, E. J. (2012). Global justice and bioethics. New York: Oxford University Press.

National Bioethics Advisory Committee. (2001). Ethical and policy issues in international research: Clinical trials in developing countries. Bethesda, MD: NBAC.

Pappworth, M. H. (1962). Human guinea pigs: A warning. London: Twentieth Century.

Pappworth, M. H. (1967). Human guinea pigs: Experimentation in man. London: Routledge.

Participants in 2006 Georgetown University Workshop on Ancillary-Care Obligations of Medical Researchers Working in Developing Countries. (2008). The ancillary-care obligations of medical researchers working in developing countries. PLoS Medicine, 20(5), e90.

Pratt, B., Ahmad, A., Cong, Y., Kumar, N., Rashid, H., Upshur, R., Van, C., \& Loff, B. (forthcoming). Perspectives from South and East Asia on clinical and research ethics: A literature review. Journal of Empirical Research on Human Research Ethics.

Presidential Commission for the Study of Bioethical Issues. (2011). "Ethically Impossible": STD Research in Guatemala from 1946-1948. Retrieved from bioethics.gov/sites/default/ files/Ethically-Impossible_PCSBI.pdf. 
Silverman, H., Strosberg, M., Luna, F., Philpott, S., \& Hemmerle, C. A. (2013, this issue). An analysis of online courses in research ethics in the fogarty-sponsored training programs. Journal of Empirical Research on Human Research Ethics, 8(5).

Sofaer, N., \& STRECH, D. (2011). Reasons why post-trial access to trial drugs should, or need not be ensured to research participants: A systematic review. Public Health Ethics, 4(2), 160-184.

Strosberg, M., Gefenas, G., \& Famenka, A. (forthcoming). Research ethics review: Identifying policy and program gaps. Journal of Empirical Research on Human Research Ethics.

TAYLOR, C. E. (1979). Clinical trials and international health research. American Journal of Public Health, 69(10), 981-983.

Thiers, F. A., Sinskey, A. J., \& Berndt, E. R. (2008). Trends in the globalization of clinical trials. Nature Reviews Drug Discovery, 7, 13-14.
VARMUS, H., \& SATcher, D. (1997). Ethical complexities of conducting research in developing countries. New England Journal of Medicine, 337(14), 1003-1005.

Vollmann, J., \& WinaU, R. (1996). Informed consent in human experimentation before the Nuremberg code. British Medical Journal, 313(7070), 1445-1449.

WassenaAR, D. (2006). Response to Coleman, C. H., \& Bouësseau, M.-C., Strengthening local review of research in Africa: Is the IRB model relevant? Bioethics Forum. Retrieved from www.thehastingscenter.org/Bioethicsforum/Post.aspx?id=322.

Weindling, P. J. (2008) The Nazi medical experiments. In E. J. Emanuel et al. (Eds.), The Oxford textbook of clinical research ethics (pp. 18-30). New York: Oxford University Press.

World Medical Association. (1964). Declaration of Helsinki. Retrieved from www.cirp.org/library/ethics/helsinki/. 